Article

\title{
Biochar-Based Graphitic Carbon Nitride Adorned with Ionic Liquid Containing Acidic Polymer: A Versatile, Non-Metallic Catalyst for Acid Catalyzed Reaction
}

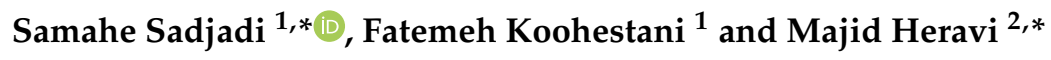 \\ 1 Gas Conversion Department, Faculty of Petrochemicals, Iran Polymer and Petrochemicals Institute, \\ P.O. Box 14975112, Tehran 1497713115, Iran; f.koohestani10@gmail.com \\ 2 Department of Chemistry, School of Science, Alzahra University, \\ P.O. Box 1993891176, Vanak, Tehran 1993891176, Iran \\ * Correspondence: samahesadjadi@yahoo.com or s.sadjadi@ippi.ac.ir (S.S.); m.heravi@alzahra.ac.ir (M.H.); \\ Tel.: +98-21-48666 (S.S.); +98-21-88044051 (M.H.); Fax: +98-21-44787021-3 (S.S.); +98-21-88041344 (M.H.)
}

Academic Editors: Sreekantha B. Jonnalagadda and Suresh Maddila

Received: 13 November 2020; Accepted: 13 December 2020; Published: 16 December 2020

\begin{abstract}
A novel biochar-based graphitic carbon nitride was prepared through calcination of Zinnia grandiflora petals and urea. To provide acidic and ionic-liquid functionalities on the prepared carbon, the resultant biochar-based graphitic carbon nitride was vinyl functionalized and polymerized with 2-acrylamido-2-methyl-1-propanesulfonic acid, acrylic acid and the as-prepared 1-vinyl-3-butylimidazolium chloride. The final catalytic system that benefits from both acidic $\left(-\mathrm{COOH}\right.$ and $\left.-\mathrm{SO}_{3} \mathrm{H}\right)$ and ionic-liquid functionalities was applied as a versatile, metal-free catalyst for promoting some model acid catalyzed reactions such as Knoevenagel condensation and Biginelli reaction in aqueous media under a very mild reaction condition. The results confirmed high activity of the catalyst. Broad substrate scope and recyclability and stability of the catalyst were other merits of the developed protocols. Comparative experiments also indicated that both acidic and ionic-liquid functionalities on the catalyst participated in the catalysis.
\end{abstract}

Keywords: ionic liquid; catalyst; biochar; graphitic carbon nitride; Knoevenagel condensation; dihydropyrimidinones

\section{Introduction}

Ionic liquids, ILs, are an interesting class of salts that are formed from organic cations and organic or inorganic anions [1-3]. A vast range of heterocycles such as imidazoles and pyridines can be utilized as organic cations in ILs. Similarly, various organic and inorganic anions can be incorporated in the structure of ILs to prepare task specific ILs [1,4,5]. The importance of ILs is due to their outstanding properties, such as high electric conductivity, low cost and thermal stability [6-8]. These features ascertained broad utility of ILs in various research sectors, including catalysis. ILs are considered as perfect, metal-free catalysts that can meet the principles of green chemistry. Mostly, ILs have been heterogenized by using conventional supporting materials.

Graphitic carbon nitride (GCN) is a metal-free, semiconductor carbon nanomaterial, containing carbon and nitrogen that can be easily prepared from cheap starting materials under calcination condition [9-12]. Among various precursors, urea is utilized frequently due to its appealing properties, such as low cost, nontoxicity and abundance [13]. Since its discovery, GCNs have found vast applications in various research domains, such as catalysis, photocatalysis, fuel cells and separation [14-17]. Regarding the catalysis, GCNs can be employed both as catalysts and catalyst supports [18]. 
Biochars (BCs) are low-cost and readily available carbon materials that can be derived from biosources through thermal treatment, such as pyrolysis, gasification and hydrothermal carbonization [19-24]. Biochars are considered as promising candidates for replacing expensive carbon materials for supporting catalytic species. However, they suffer from some drawbacks, such as a lack of functional groups and low textural properties [25-29]. To handle these issues, and improve the features of biochars, they are mostly treated chemically or physically.

Knoevenagel condensation is one of the well-established chemical transformations that leads to the formation of $\alpha, \beta$-unsaturated chemicals [30,31]. This is a fundamental reaction that is extensively used for the synthesis of drugs, functional polymers and many important fine chemicals, such as dyes, herbicides, fragrances and optoelectronic materials. This reaction is usually catalyzed by basic [32-34] or acidic catalysts [35-37]. To promote this reaction, various catalysts, including metallic and non-metallic catalysts can be utilized [38-40].

The conventional reaction, used for the synthesis of dihydropyrimidinones (DHPMs) is the Biginelli reaction. This reaction has disadvantages, such as harsh reaction conditions, prolonged time, poor yields due to the formation of side products, and use of various volatile organic solvents. Hence, many catalytic systems have been improved for the synthesis of DHPMs, including magnetic catalysts [41-43], ionic liquids [44-46], carbohydrate [47,48], Bronsted acids [49-51] and Lewis acid [52-54]. On the other hand, the importance of this reaction lies in the biological properties of DHPMs and wide utility for pharmaceutical purposes, such as antiviral, antimalarial, antihypertensive, antifungal, antitubercular and antibacterial properties [55-57]. This multicomponent reaction is mostly promoted by an appropriate catalyst [58-61].

We are interested in developing heterogeneous catalysts with the use of natural raw materials [62-65]. In this line, we have recently reported non-metallic catalysts that were designed by introduction of ILs or acidic moieties on a natural supporting material $[8,66]$. In the continuation of our studies, we wish to report a versatile catalyst, BC@GCN-P-IL, that benefits from both acidic and IL moieties.

\section{Results and Discussion}

To prepare the catalyst, Zinnia grandiflora petals were mixed with urea and calcined to furnish biochar-based graphitic carbon nitride (BC@GCN). The latter, was then vinyl functionalized with 3-(trimethoxysilane) propyl methacrylate (3-TMSPMA) to furnish BC@GCN-V and subsequently tolerated polymerization reaction with 1-vinylimidazole, 2-acrylamido-2-methyl-1-propanesulfonic acid (AMPS) and acrylic acid (AA), Figure 1. The polymeric moiety (P-IL) that has been grown on BC@GCN contained both acidic $\left(-\mathrm{COOH}\right.$ and $\left.-\mathrm{SO}_{3} \mathrm{H}\right)$ [66] and IL moieties on its backbone. Hence, it was assumed that it could promote various classic, acid-catalyzed chemical transformations efficiently under mild reaction condition. To verify this issue, the activity of the catalyst for the Knoevenagel condensation reaction and Biginelli reaction was examined. Moreover, the catalyst recyclability and the stability of the reused catalyst were studied. On the other hand, in a comparative study, the contribution of the hybrid components to the catalysis was appraised. 


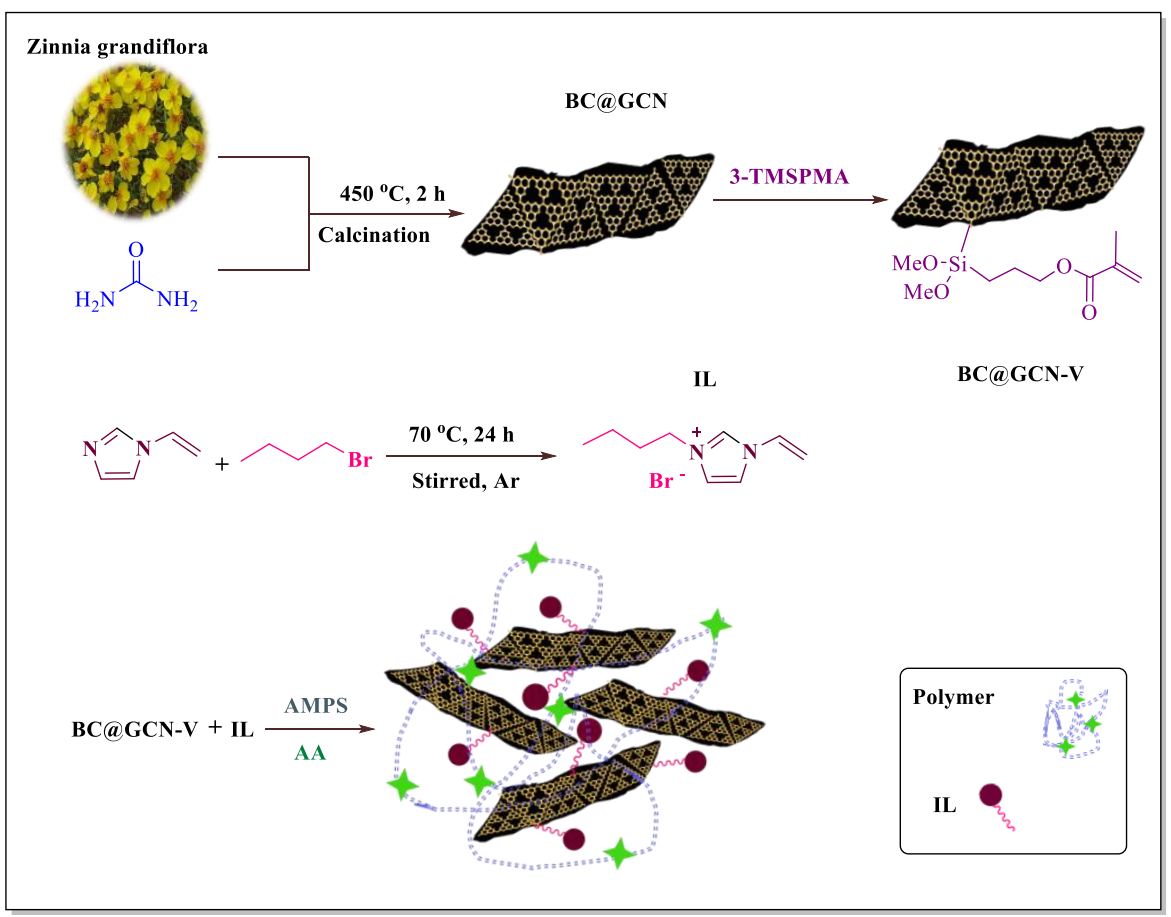

Figure 1. Schematic illustration of preparation of BC@GCN-P-IL.

\subsection{Validation of Formation of BC@GCN-P-IL}

In Figure 2, the FE-SEM images of BC@GCN-P-IL are presented. As depicted, the catalyst exhibited aggregated-like morphology. Aggregation can be induced by the non-covalent interactions, such as hydrogen bonds and electrostatic interactions between the functionalities on BC@GCN-P-IL. Comparison of the images of the catalyst with that of BC@GCN, Figure 2, indicated that the two samples exhibited distinguished morphologies. More precisely, introduction of the polymeric moiety on BC@GCN changed its morphology.
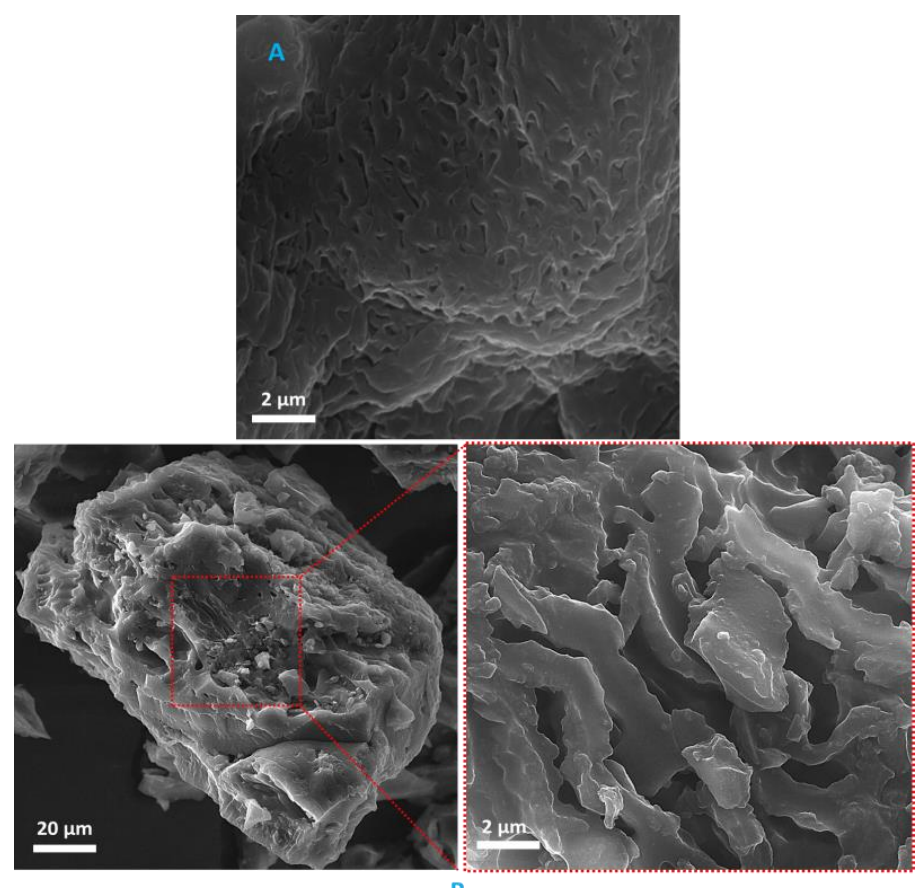

Figure 2. (A) FE-SEM image of BC@GCN and (B) FE-SEM images of BC@GCN-P-IL. 
Energy dispersive spectroscopy (EDS) analysis was also performed to further analyze BC@GCN-P-IL. As shown in Figure 3, C, N, O, Br, Si and S atoms were detected in EDS analysis. $\mathrm{C}, \mathrm{N}$ and $\mathrm{O}$ atoms are representative of BC@GCN. Notably, $\mathrm{C}$ and $\mathrm{O}$ atoms are also indicative of AA. The presence of $\mathrm{Br}$, along with $\mathrm{C}$ and $\mathrm{N}$ atoms, on the other hand, can be ascribed to the P-IL moiety.

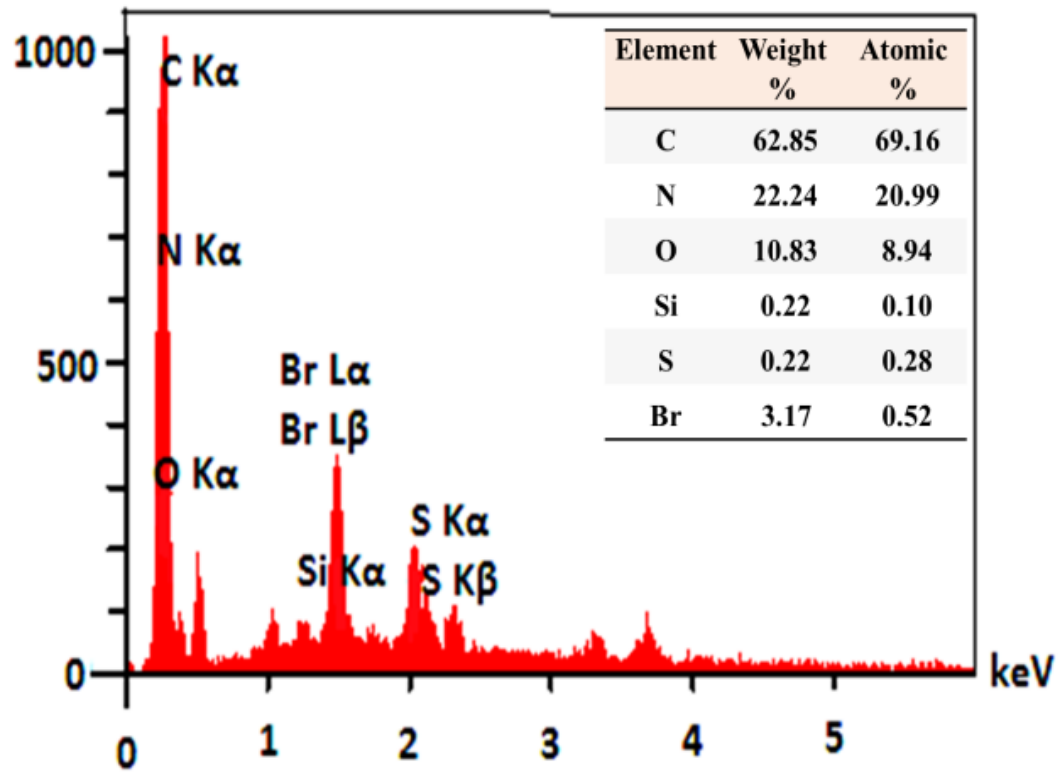

Figure 3. EDS analysis of BC@GCN-P-IL.

Mapping analysis of BC@GCN-P-IL is depicted in Figure 4. As illustrated, S atoms were almost uniformly dispersed. N, C and $\mathrm{Br}$ atoms were also dispersed homogeneously, approving the uniform dispersion of IL on BC@GCN.
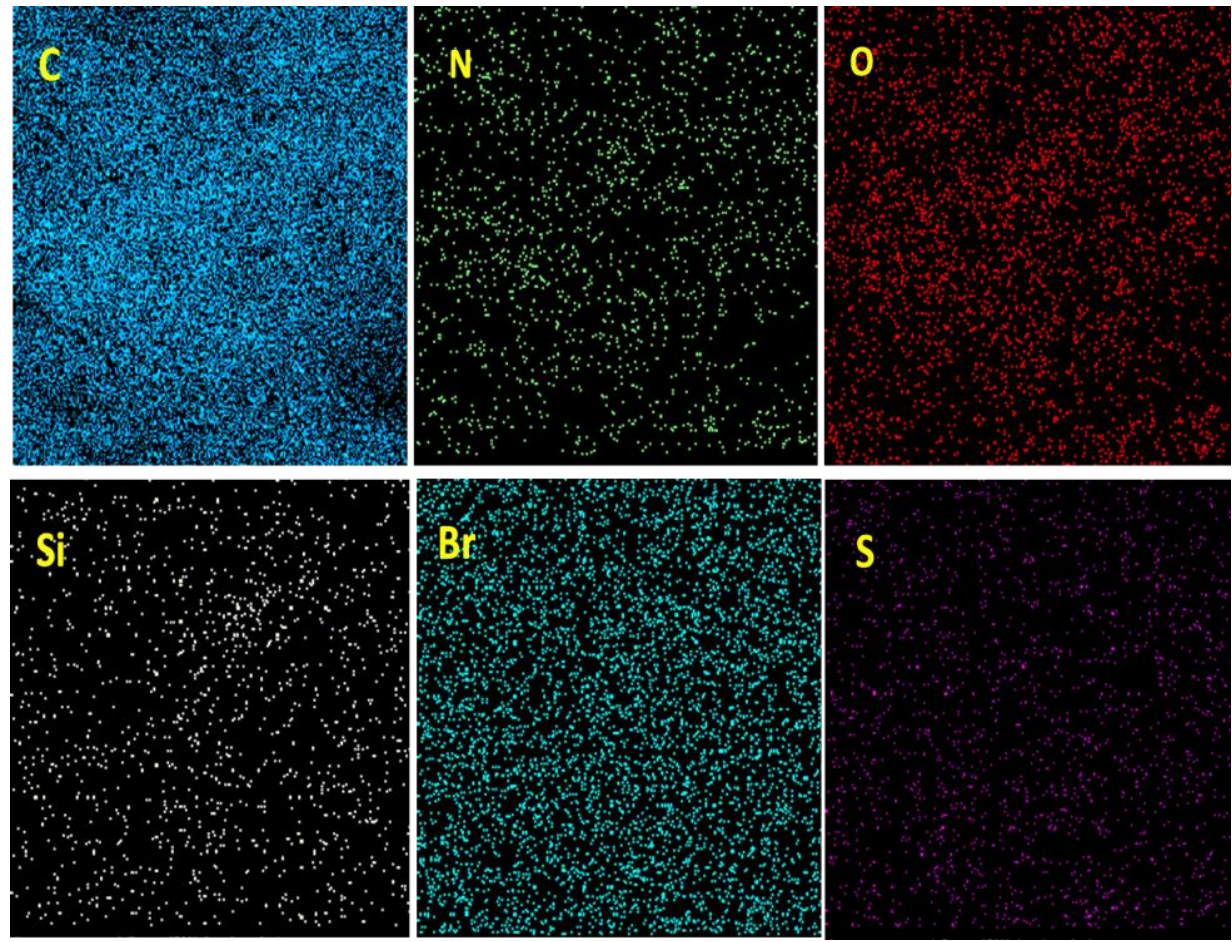

Figure 4. Elemental mapping analysis of BC@GCN-P-IL. 
To further approve the conjugation of P-IL on the backbone of the catalyst, TG curves of BC@GCN and BC@GCN-P-IL were recorded, Figure 5. Comparison of the two recorded curves demonstrated that the thermal stability of BC@GCN-P-IL was inferior compared to BC@GCN. In fact, BC@GCN exhibited only two weight losses at $120^{\circ} \mathrm{C}$ and $510{ }^{\circ} \mathrm{C}$ [67]. In the TG curve of BC@GCN-P-IL, an additional weight loss at the range of $240-320^{\circ} \mathrm{C}(10 \mathrm{wt} \%)$ could be detected that corresponded to the degradation of P-IL.

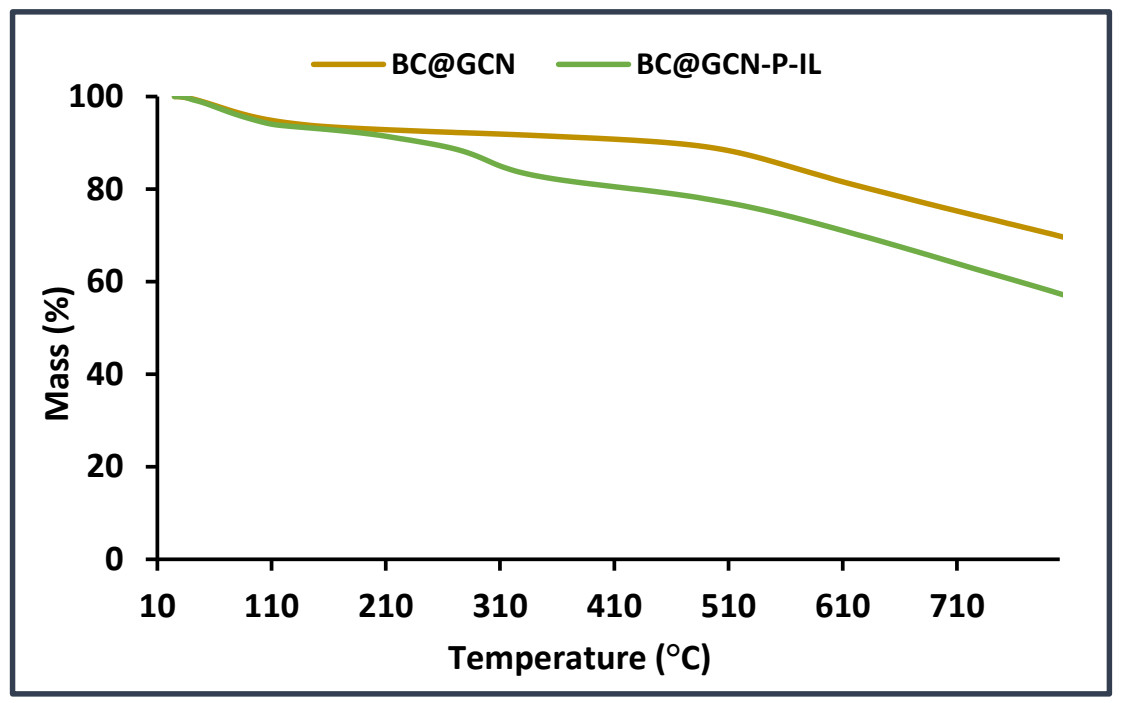

Figure 5. Thermograms of BC@GCN and BC@GCN-P-IL.

The next characterization technique was FTIR spectroscopy. To verify the formation of each intermediate, the FTIR spectra of BC@GCN, BC@GCN-V and BC@GCN-P-IL were recorded and compared, Figure 6. As illustrated, the FTIR spectrum of BC@GCN showed the absorbance bands at $3418 \mathrm{~cm}^{-1}$ (-OH functionality), $2920 \mathrm{~cm}^{-1}\left(-\mathrm{CH}_{2}\right.$ functionality), $1623 \mathrm{~cm}^{-1}$ (-C=C functionality), $1033 \mathrm{~cm}^{-1}$ and $1409 \mathrm{~cm}^{-1}$ (-C-O functionality). The FTIR spectrum of BC@GCN-V contained the absorbance bands observed in BC@GCN. Moreover, an additional band at $1723 \mathrm{~cm}^{-1} \mathrm{can}$ be discerned in this spectrum that is indicative of conjugation of 3-TMSPMA. FTIR spectrum of BC@GCN-P-IL also exhibited the bands of BC@GCN and an additional band at $1700 \mathrm{~cm}^{-1}$ that is indicative of the carbonyl functionality in polymeric moiety. Notably, the main characteristic band of IL moiety, i.e., $-\mathrm{C}=\mathrm{N}$ band overlapped with the bands of BC@GCN.

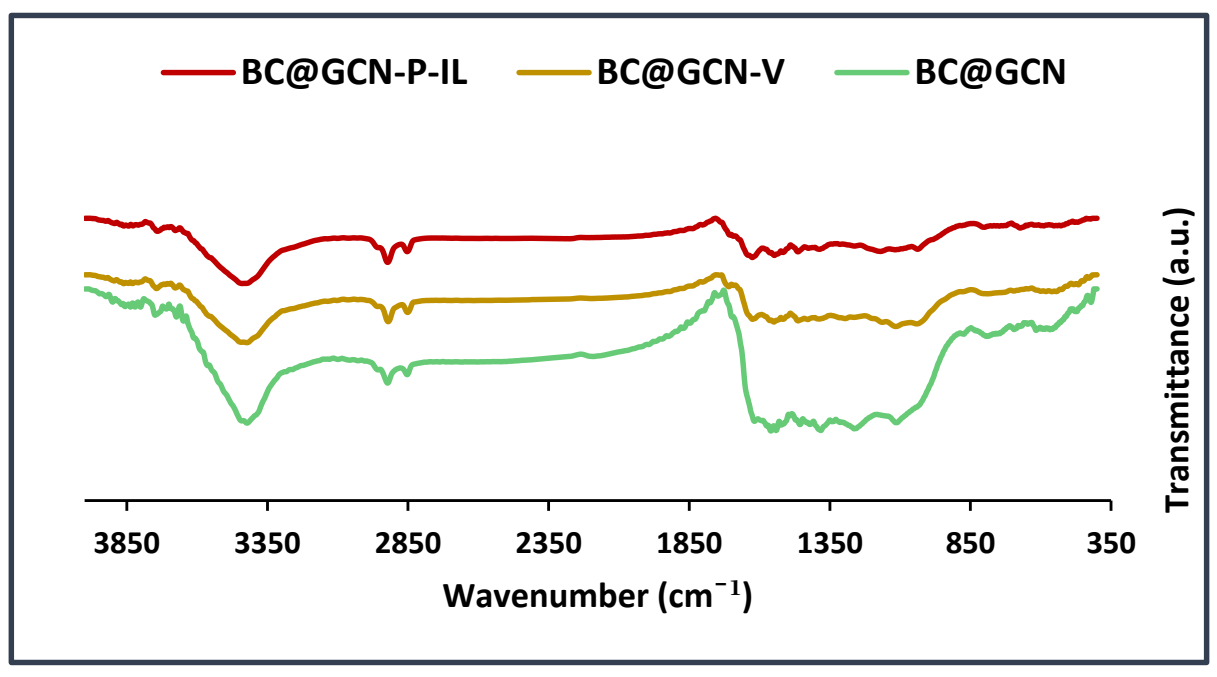

Figure 6. FTIR spectra of BC@GCN, BC@GCN-V and BC@GCN-P-IL. 
The XRD pattern of BC@GCN-P-IL was recorded, Figure S1, to study the crystal phase of the catalyst. According to the literature, the polymeric moiety on the BC@GCN is amorphous and it is expected to observe its characteristic band at $2 \theta=20-30^{\circ}$ [18]. The distinguishing band of BC@GCN is also appeared in the same range. As shown in Figure 7, in the XRD pattern of BC@GCN-P-IL a peak can be discerned in the range of $2 \theta=25-30^{\circ}$. This result is in good accordance with the literature [18].

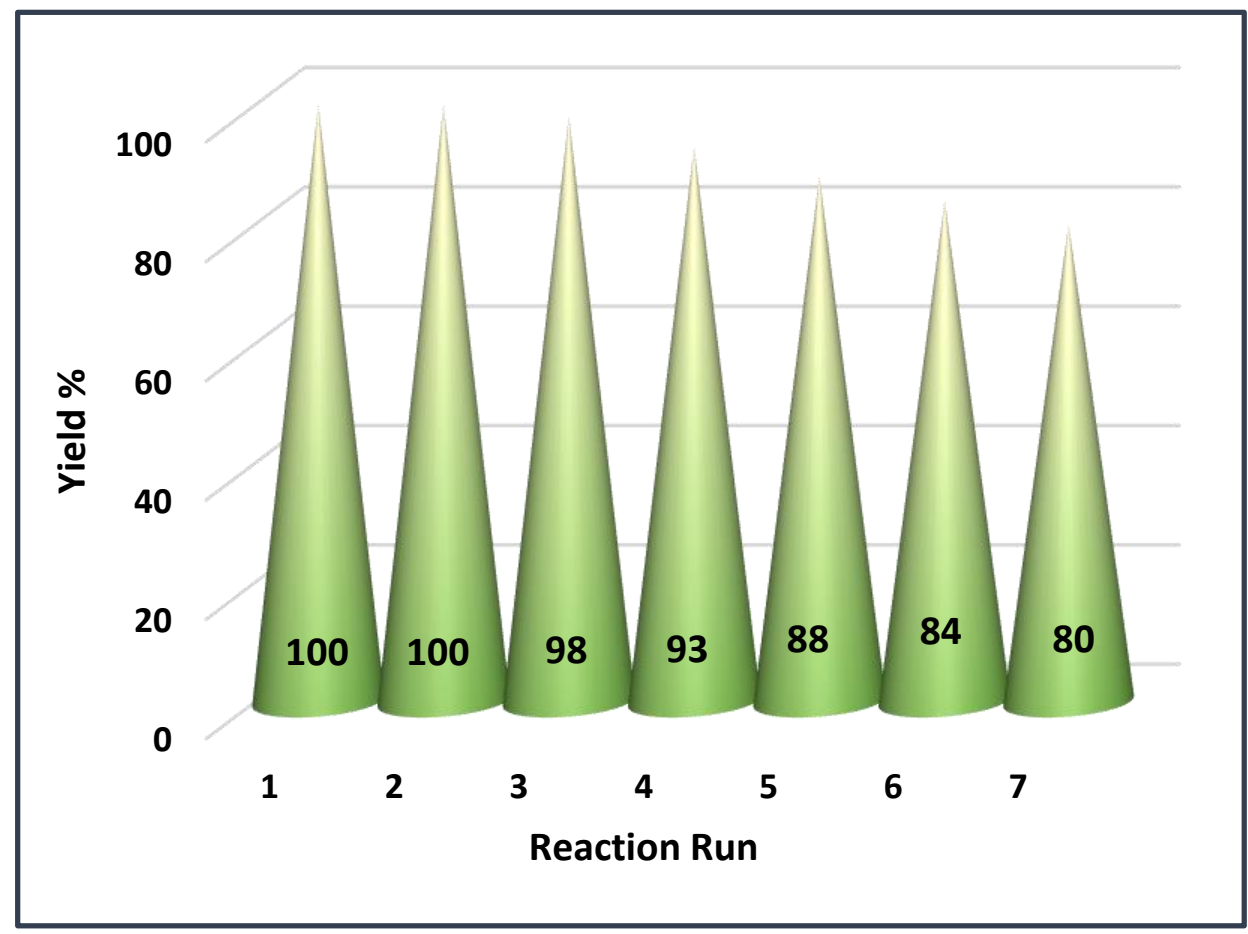

Figure 7. The recyclability of BC@GCN-P-IL for the model Biginelli reaction under its optimum reaction condition.

\subsection{Catalyst Activity}

In this research, we targeted preparation of a metal-free catalyst that could catalyze conventional chemical transformations in aqueous media under a mild reaction condition. In this regard, BC@GCN was prepared and then, a polymeric moiety that contained both IL and acid functionalities $\left(-\mathrm{SO}_{3} \mathrm{H}\right.$ and $\left.-\mathrm{COOH}\right)[66,68]$ was incorporated to the structure of the catalyst. It was assumed that both IL and acidic functionalities could effectively promote the acid-catalyzed reactions. To verify this assumption, first, the performance of BC@GCN-P-IL for Knoevenagel condensation that is a widely used chemical reaction was appraised. To this purpose, malononitrile and benzaldehyde were reacted at ambient temperature in water in the presence of $20 \mathrm{mg}$ BC@GCN-P-IL. Gratifyingly, it was found out that after $2 \mathrm{~h}$, the reaction completed and furnished the desired product in $100 \%$ yield. Next, it was elucidated whether reagents with different electronic features could also tolerate this reaction. In this line, several benzaldehydes with electron donating and electron withdrawing groups were examined as starting materials. Gratifyingly, the reactions of all of the studied substrates resulted in the corresponding products in excellent yields, Table 1. Even ketones and aromatic aldehydes could also undergo this reaction to give the products high yields. 
Table 1. Knoevenagel condensation reactions of various aldehydes with malononitrile catalyzed by BC@GCN-P-IL a .

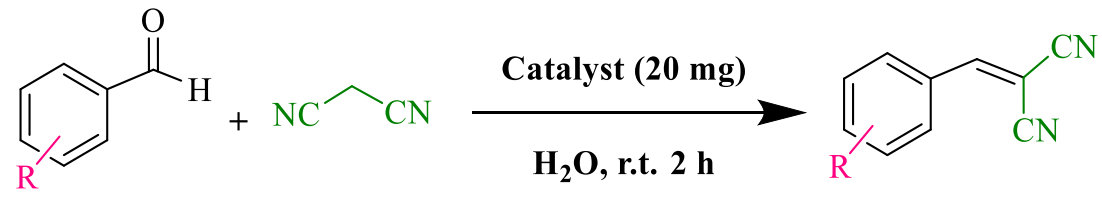

\begin{tabular}{|c|c|c|}
\hline NO. & Substrate & Yield (\%) ${ }^{b}$ \\
\hline 1 & Benzaldehyde & 100 \\
\hline 2 & 4- $\mathrm{NO}_{2}$-benzaldehyde & 98 \\
\hline 3 & 2- $\mathrm{NO}_{2}$-benzaldehyde & 95 \\
\hline 4 & 3- $\mathrm{NO}_{2}$-benzaldehyde & 95 \\
\hline 5 & 4-Me-benzaldehyde & 98 \\
\hline 6 & 4-MeO-benzaldehyde & 97 \\
\hline 7 & 2-MeO-benzaldehyde & 95 \\
\hline 8 & 4-Cl-benzaldehyde & 100 \\
\hline 9 & Furfural & 90 \\
\hline 10 & Acetophenone & 85 \\
\hline
\end{tabular}

a Reaction condition: Substrate $(1 \mathrm{mmol})$, malononitrile $(1.2 \mathrm{mmol})$ and BC@GCN-P-IL $(20 \mathrm{mg})$ in $\mathrm{H}_{2} \mathrm{O}$ at $25{ }^{\circ} \mathrm{C}$ in $2 \mathrm{~h} .{ }^{\mathrm{b}}$ Isolated yields.

To further reveal the merit of BC@GCN-P-IL for Knoevenagel condensation, the yield of the model Knoevenagel condensation under BC@GCN-P-IL catalysis was compared with some published methodologies. The yields of the desired product, recyclability and reaction parameters for each methodology are reported in Table 2. It is clear that this key reaction could be promoted by various catalysts, including metallic and non-metallic ones. In some tabulated procedures, use of precious metals or metal organic frameworks (MOFs) was reported that led to high yields of the desired product. Notably, fabrication of MOFs mostly needs precise procedure. On the other hand, use of non-metallic catalysts can be more environmentally benign. As shown, some non-metallic catalysts, such as glycine were not effective and resulted in moderate yields after a long reaction time. Regarding the reaction temperature, it can be seen that this reaction has been reported both at ambient and elevated temperatures. Regarding the reaction time, it can be concluded that the required reaction time for BC@GCN-P-IL was relatively low. Notably, in some tabulated procedure, the reaction times were shortened by use of ultrasonic irradiation or using metallic catalysts. Considering the recyclability of the catalyst, it can be seen that BC@GCN-P-IL exhibited good recyclability, comparable to some most of the tabulated catalysts.

The data presented in Table 2 could corroborate that metal-free BC@GCN-P-IL could perform under a mild reaction condition to give the condensation product in high yield.

Approving high activity of BC@GCN-P-IL for Knoevenagel condensation reaction, it was investigated whether this catalyst could promote more complex acid-catalyzed reactions. To this purpose, the one-pot, three-component Biginelli reaction for the synthesis of dihydropyrimidinones was targeted. Optimization of the reaction condition for a model Biginelli reaction, reaction of benzaldehyde, urea and ethyl acetoacetate, confirmed that using low content of the catalyst $(0.03 \mathrm{~g})$ in 1:1 mixture of $\mathrm{H}_{2} \mathrm{O} / \mathrm{EtOH}$ at $50{ }^{\circ} \mathrm{C}$, the reaction could proceed to furnish the desired product in $100 \%$ yield. Study of the generality of the present protocol, Table 3, also confirmed that this procedure could be generalized to various substrates with different electronic properties.

The results of the study of the catalytic activity of the catalyst confirmed that the developed catalyst could be considered as a versatile catalyst for promoting various acid-catalyst reactions. 
Table 2. The comparison of BC@GCN-P-IL-based procedure for the model Knoevenagel condensation reaction (malononitrile and benzaldehyde) with some reported ones [69-74].

\begin{tabular}{|c|c|c|c|c|c|c|c|}
\hline Entry & Catalyst & Temp. ${ }^{\circ} \mathrm{C}$ & Solvent & Time (h:min) & Recycle Run & Yield (\%) & Ref. \\
\hline 1 & Glycine & 25 & {$\left[6-\mathrm{mim}^{2} \mathrm{PF}_{6}\right.$} & $22: 00$ & 2 & 77 & [69] \\
\hline 2 & Caffein-SiO ${ }_{2} @ \mathrm{Fe}_{3} \mathrm{O}_{4}$ & 60 & $\mathrm{H}_{2} \mathrm{O}$ (ultrasonic irradiation) & 00:06 & 5 & 94 & {$[70]$} \\
\hline 3 & Activated $\mathrm{Hf}-\mathrm{UiO}-66-\mathrm{N}_{2} \mathrm{H}_{3}$ & 25 & $\mathrm{EtOH}$ & 4:00 & 5 & 98 & [71] \\
\hline 4 & {$\left[\mathrm{H}_{3} \mathrm{~N}^{+}-\mathrm{CH}_{2}-\mathrm{CH}_{2}-\mathrm{OH}\right]\left[\mathrm{CH}_{3} \mathrm{COO}^{-}\right] \mathrm{IL}$} & 25 & Solvent free & $<1: 00$ & 5 & 90.9 & [72] \\
\hline 5 & PdNi@GO & 25 & $\mathrm{H}_{2} \mathrm{O} / \mathrm{EtOH}$ & 00:08 & 5 & 95 & [73] \\
\hline $6^{a}$ & {$\left[\mathrm{Zn}_{2}(\mathrm{TCA})(\mathrm{BIB})_{2,5}\right] \cdot\left(\mathrm{NO}_{3}\right)$} & 60 & Solvent free & $1: 00$ & 4 & $>99$ & {$[74]$} \\
\hline 7 & BC@GCN-P-IL & 25 & $\mathrm{H}_{2} \mathrm{O}$ & 2:00 & 5 & 100 & This work \\
\hline
\end{tabular}

${ }^{\mathrm{a}}\left[\mathrm{Zn}_{2}\right.$ (tricarboxytriphenyl amine)(1,3(imidazol-1-ylmethyl)benzene) $\left.{ }_{2,5}\right] .\left(\mathrm{NO}_{3}\right)$. 
Table 3. BC@GCN-P-IL catalyzed synthesis of dihydropyrimidinones ${ }^{\text {a }}$.

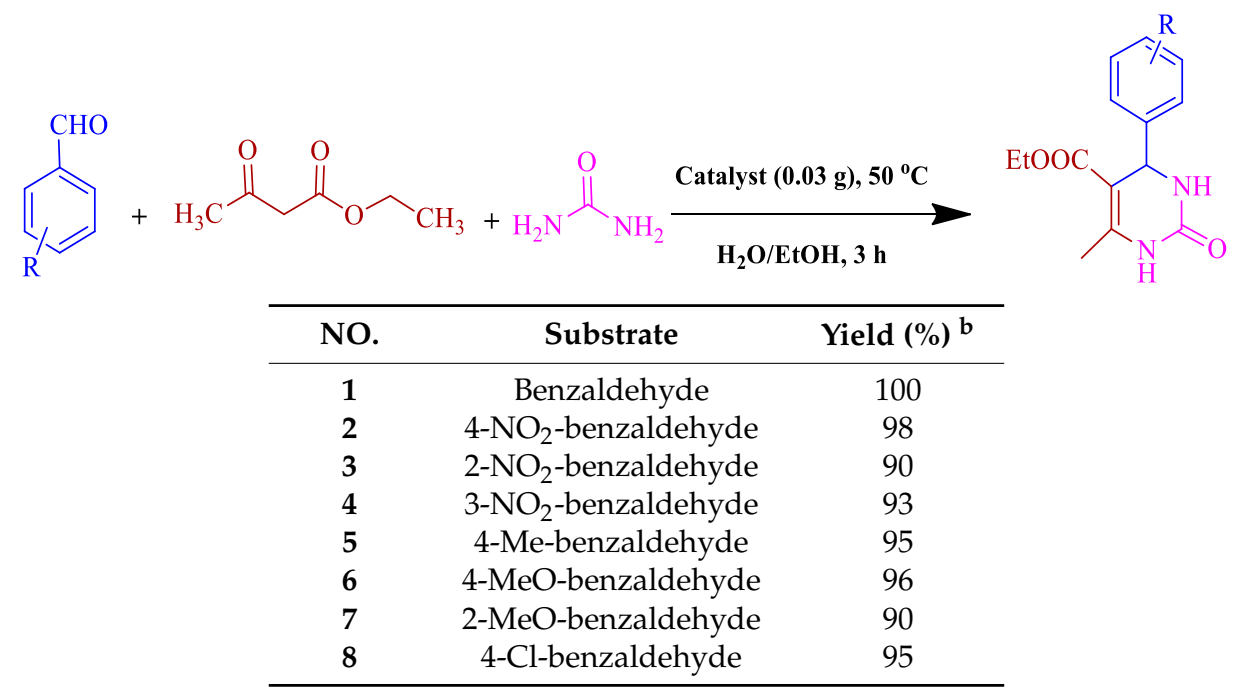

a Reaction condition: substrate $(1 \mathrm{mmol})$, ethyl acetoacetate $(1 \mathrm{mmol})$, urea $(1.3 \mathrm{mmol})$, catalyst $(30 \mathrm{mg})$, $\mathrm{H}_{2} \mathrm{O} / \mathrm{EtOH}(10 \mathrm{~mL})$ at $50{ }^{\circ} \mathrm{C}$ in $3 \mathrm{~h} .{ }^{\mathrm{b}}$ Isolated yields.

\subsection{Appraising the Contribution of Catalyst Moieties to the Catalysis}

As BC@GCN-P-IL contained several functionalities, such as acidic and IL functionalities in its structure, the contribution of each moiety to the catalysis need to be studied. To shed light to this issue, preparation of some control samples and comparing their activities for a model reaction were imperative. To this purpose, the model Knoevenagel condensation reaction was selected for appraising the contribution of the catalyst moieties. For the first step, BC@GCN was prepared and used as a catalyst for promoting the model Knoevenagel condensation reaction. The result showed that using this catalyst the reaction led to only $60 \%$, Table 4 , of the desired product. Comparison of the activity of BC@GCN with that of BC@GCN-P-IL indicated superior activity of the latter. As the activity of BC@GCN was lower than that of BC@GCN-P-IL, it could be concluded that P-IL could contribute to the catalysis. To scrutinize the role of P-IL in the catalysis, two control samples, BC@GCN-P and BC@GCN-IL, were prepared. In BC@GCN-P, the polymeric network was formed from polymerization of AMPS and AA, while in BC@GCN-IL, the polymeric moiety was formed from polymerization of the as-prepared IL. In fact, in BC@GCN-P, the catalyst benefited from the acidic functionalities $\left(-\mathrm{COOH}\right.$ and $\left.-\mathrm{SO}_{3} \mathrm{H}\right)$, while in BC@GCN-IL, the catalyst possessed IL functionalities. Investigation of the catalytic activities of these two samples approved their superior activities compared to BC@GCN. This result established that the introduction of either IL or acidic functionalities was favorable for the catalytic activity. On the other hand, comparison of the activities of these two samples with that of BC@GCN-P-IL implied the higher activity of the latter. This issue corroborated that simultaneous incorporation of both IL and acidic functionalities in the backbone of the catalyst was beneficiary for the catalytic activity.

Table 4. The comparison of the efficiency of BC@GCN-P-IL with control samples for model Knoevenagel condensation reaction (reaction of malononitrile and benzaldehyde) under optimum condition.

\begin{tabular}{ccc}
\hline Entry & Catalyst & Yield \% \\
\hline $\mathbf{1}$ & BC@GCN & 60 \\
$\mathbf{2}$ & BC@GCN-P & 85 \\
$\mathbf{3}$ & BC@GCN-IL & 90 \\
$\mathbf{4}$ & BC@GCN-P-IL & 100 \\
\hline
\end{tabular}




\subsection{Recyclability of BC@GCN-P-IL}

To commence the study of the recyclability of BC@GCN-P-IL, the recovered catalyst from the model Biginelli reaction was reused for the next run of this multicomponent reaction under the reported optimum reaction condition. The measurement of the yield of the model Biginelli reaction indicated that BC@GCN-P-IL maintained its activity for the second run of the reaction. Upon further reuse, slight decrease of the activity of BC@GCN-P-IL was discerned and the yield of the model Biginelli reaction reached to $80 \%$ after seven runs of the reaction, Figure 7.

In the next part of this research, the recycled BC@GCN-P-IL was characterized via FTIR spectroscopy to elucidate the origin of the decrement of its activity. As shown in Figure 8, the FTIR spectrum of the recycled BC@GCN-P-IL was distinguished from fresh BC@GCN-P-IL. As shown, the intensities of the absorbance bands in fresh and reused catalysts were different. On the other hand, some new absorbance bands could be observed in the recycled catalyst. For example, the bands at $744-780 \mathrm{~cm}^{-1}$ and sharp bands at $1350-1400 \mathrm{~cm}^{-1}$ could be discerned in the FTIR spectrum of the reused catalyst. This issue can be attributed to the deposition of the products on BC@GCN-P-IL. In fact, coverage of the active sites of BC@GCN-P-IL could justify the observed loss of the activity.

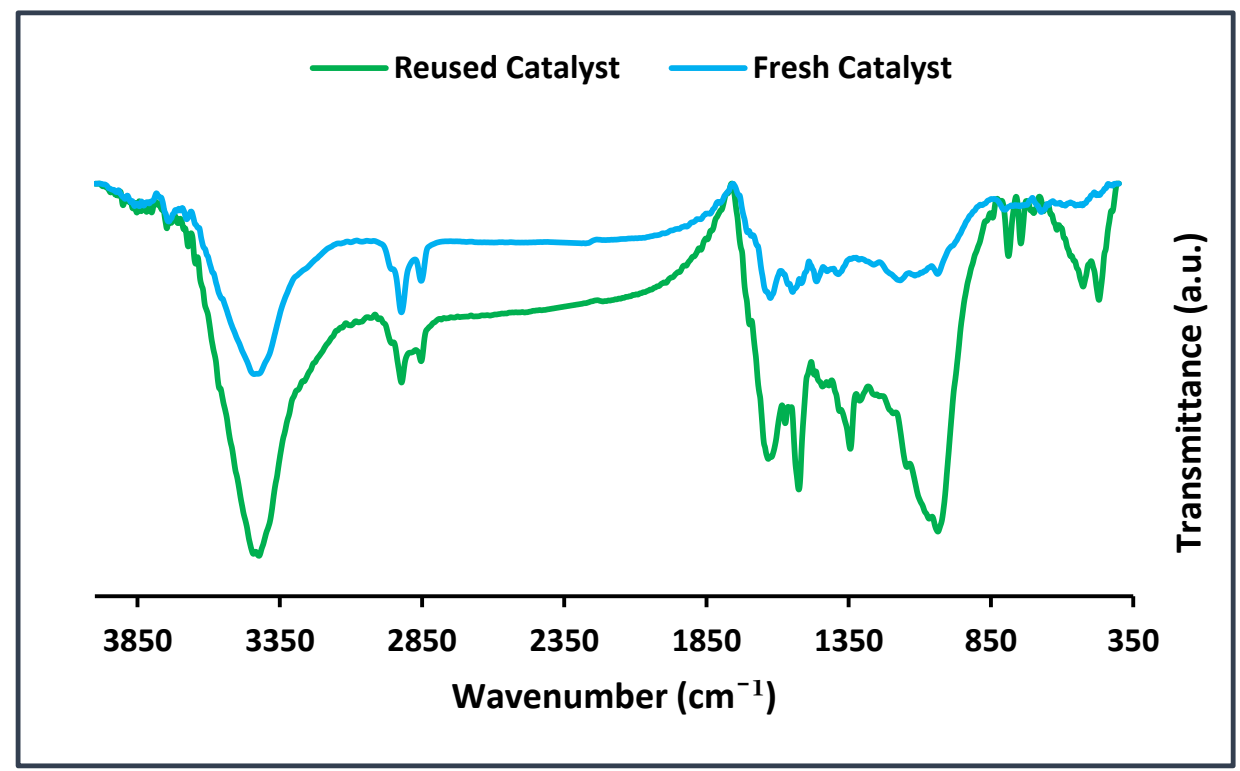

Figure 8. FTIR spectra of the recycled and fresh BC@GCN-P-IL after seven runs of the Biginelli reaction.

\section{Materials and Methods}

In this research, Zinnia grandiflora petals were collected in the north of Iran and used as the biochar source. Other chemicals utilized for the preparation of the catalytic system included, 3-(trimethoxysilane) propyl methacrylate (3-TMSPMA), urea, 1-vinylimidazole (VIM), 1-bromobutane, 2,2'-azobis (2-methylpropionitrile) (AIBN), 2-acrylamido-2-methyl-1-propanesulfonic acid (AMPS), acrylic acid (AA), toluene, diethyl ether and $\mathrm{EtOH}$. All of the so-called reagents were purchased from Sigma-Aldrich (Darmstadt, Germany). The chemicals used for performing the Knoevenagel condensation reaction and Biginelli reaction were aldehydes, malononitrile, ethyl acetoacetate, urea and $\mathrm{EtOH}$, all provided from Sigma-Aldrich.

\subsection{Apparatus}

After preparation of the catalytic system, it was verified by various techniques. Fourier transform infrared (FTIR) spectral analysis was performed with KBr pellets method via PERKIN-ELMER-Spectrum 65 (Bruker, Germany). Thermogravimetric analysis (TGA) was accomplished using a (METTLER TOLEDO, model Leicester, Leicester, UK) under $\mathrm{N}_{2}$ atmosphere with heating rate of $10{ }^{\circ} \mathrm{C} \mathrm{min}-1$. 
The X-ray diffraction (XRD) pattern was recorded on Siemens, D5000 apparatus using graphite monochromatic $\mathrm{Cu}-\mathrm{K} \alpha$ (Karlsruhe, Germany). Field emission scanning electron microscope (FE-SEM) images and energy dispersive spectroscopy (EDS) were gathered by using MIRA 3-XMU (Tescan Co., Brno, Czech Republic). All of the organic compounds synthesized from Biginelli and Knoevenagel condensation reactions were synthetic. Hence, their characterization was performed by comparing their spectral data $\left({ }^{1} \mathrm{H} N M R,{ }^{13} \mathrm{C}\right.$ NMR and FTIR) with authentic samples.

\subsection{Synthesis of the Catalyst}

\subsubsection{Synthesis of BC@GCN}

Preparation of biochar-based graphitic carbon nitride was carried out according to the previously reported procedure with some modification $[75,76]$. In this work, Zinnia grandiflora petals, collected from the north of Iran, were utilized for the first time as biosources. Biosource was rinsed with deionized water repeatedly, air-dried and then transformed to powder by using a mixer. In order to prepare biochar-based graphitic carbon nitride, urea $(5 \mathrm{~g})$ was thoroughly mixed with Zinnia grandiflora powder $(5 \mathrm{~g})$ and ground for $10 \mathrm{~min}$ in a mortar. The resulting powder was then calcined in a tubular furnace under $\mathrm{N}_{2}$ atmosphere at $450{ }^{\circ} \mathrm{C}$ for $2 \mathrm{~h}$. Afterwards, the furnace was cooled down to room temperature and the product, BC@GCN, was taken out.

\subsubsection{Synthesis of BC@GCN-V}

To vinyl-functionalize BC@GCN, $2 \mathrm{~g}$ of BC@GCN was dispersed in toluene $(60 \mathrm{~mL})$ under stirring for about $30 \mathrm{~min}$. Then, $2 \mathrm{~mL}$ of 3-TMSPMA was gradually added to the abovementioned suspension. After stirring for $10 \mathrm{~min}$, the mixture was refluxed for $24 \mathrm{~h}$. Finally, the solid product was filtered, washed with toluene and dried at $60^{\circ} \mathrm{C}$ overnight.

\subsubsection{Synthesis of BC@GCN-P-IL}

First, IL monomer was prepared. In this regard, VIM $(2 \mathrm{~mL})$ and excess amount of 1-bromobutane were mixed in a $50 \mathrm{~mL}$ round-bottomed flask and kept at $70{ }^{\circ} \mathrm{C}$ for $24 \mathrm{~h}$ under stirring. Upon completion of the reaction, the obtained mixture was allowed to cool at ambient temperature, and then diethyl ether was introduced to furnish a light-brown viscous IL. Finally, the diethyl ether was removed from the reaction system under vacuum and the product was washed with $\mathrm{MeOH}$ for three times and dried at room temperature.

In the next step, using the as prepared IL monomer and two other monomers (AA and AMPS), BC@GCN was adorned with a polymeric moiety, P-IL, containing IL and acidic functionalities. Typically, BC@GCN-V $(1 \mathrm{~g})$ was added to $\mathrm{EtOH} / \mathrm{H}_{2} \mathrm{O}(30 \mathrm{~mL}, 2: 1)$ and suspended by ultrasonic. Afterward, AIBN $(0.1 \mathrm{~g})$ as the polymerization initiator was introduced to the so-called suspension under inert atmosphere and the obtained mixture was heated up to $70^{\circ} \mathrm{C}$. After $30 \mathrm{~min}$, aqueous solutions of AMPS $(1 \mathrm{~mL}), \mathrm{AA}(1 \mathrm{~mL})$ and IL $(1.5 \mathrm{~g})$ were added into the above mentioned mixture and the polymerization was continued for one day under stirring conditions. Finally, the solid product was filtered, washed tree times with $\mathrm{EtOH}$ and dried under vacuum at $60^{\circ} \mathrm{C}$.

\subsection{Evaluation of the Catalytic Activity}

\subsubsection{Knoevenagel Condensation Reaction}

Typically, all of the reagents, i.e., aldehyde $(1 \mathrm{mmol})$ and malononitrile $(1.2 \mathrm{mmol})$ were mixed in $\mathrm{H}_{2} \mathrm{O}$ and then BC@GCN-P-IL $(0.02 \mathrm{~g})$ was added. The obtained mixture was stirred for $2 \mathrm{~h}$ at ambient temperature. Knoevenagel condensation was simply traced by TLC (Merck Co., Readington, NJ, USA). At the end, $\mathrm{MeOH}(10 \mathrm{~mL})$ was added and BC@GCN-P-IL was separated through conventional filtration. The recovered catalyst was reused five times in the model reaction after washing with $\mathrm{MeOH}$ and drying at $70{ }^{\circ} \mathrm{C}$ overnight. To obtain the Knoevenagel condensation products, the solvent was evaporated 
under vacuum and products were purified by column chromatography (ethyl acetate/hexane 1:5) (Agilent, Santa Clara, CA, USA). All of the products were synthetic [66] and their characterization was performed by comparing their melting points and spectral data $\left({ }^{1} \mathrm{H} \mathrm{NMR}\right.$ and ${ }^{13} \mathrm{C}$ NMR) with authentic samples. Moreover, the yields of the reactions were estimated by using GC (Agilent, USA).

\subsubsection{Biginelli Reaction}

This one-pot reaction was performed by mixing aldehyde $(1 \mathrm{mmol})$, ethyl acetoacetate $(1 \mathrm{mmol})$, urea $(1.3 \mathrm{mmol})$ and BC@GCN-P-IL (0.03 g) in $\mathrm{H}_{2} \mathrm{O}$ : EtOH $(10 \mathrm{~mL}, 1: 2)$ and heating up to $50{ }^{\circ} \mathrm{C}$. Monitoring the reaction by TLC confirmed that the reaction completed after $3 \mathrm{~h}$. After completion of the reaction, $\mathrm{MeOH}$ was poured to the reaction vessel and BC@GCN-P-IL was separated, washed with $\mathrm{EtOH}$ and reused seven times in model reactions without a significant loss of activity. To obtain DHPMs, the solvent in the filtrate was evaporated and the resulting DHPM was rinsed with EtOH. Furthermore, with the aid of column chromatography (using ethyl acetate/hexane mixture) the product was purified. All of the products were synthetic [77] and their characterization was performed by comparing their melting points and spectral data ( ${ }^{1} \mathrm{H}$ NMR and FTIR) with authentic samples. Moreover, the yields of the reactions were estimated by using GC.

\section{Conclusions}

Using Zinnia grandiflora petals and urea as a nitrogen source, a novel biochar-based graphitic carbon nitride, BC@GCN, was fabricated. To introduce functionalities on BC@GCN, it was vinyl functionalized and reacted with AMPS, AA and IL in the presence of AIBN. The formed polymeric network on BC@GCN contained both acidic (-COOH and $\left.-\mathrm{SO}_{3} \mathrm{H}\right)$ and IL functionalities and rendered the hybrid system, BC@GCN-P-IL, an efficient catalyst for promoting acid catalyzed reactions such as Knoevenagel condensation and Biginelli reaction in aqueous media under a very mild reaction condition. The developed protocols could be generalized to various substrates. Moreover, BC@GCN-P-IL could be successfully recovered and reused for several reaction runs. Using some control catalysts, it was found that introduction of P-IL that contained the acidic and IL functionalities on BC@GCN dramatically increased the catalytic activity.

Supplementary Materials: FE-SEM image of BC@GCN is available online.

Author Contributions: Conceptualization, F.K.; methodology, software, formal analysis, original draft preparation, data curation, S.S.; validation, investigation, resources, writing-review and editing, visualization, supervision, project administration, funding acquisition, M.H.; supervision, project administration, funding acquisition. All authors have read and agreed to the published version of the manuscript.

Funding: This research received no external funding.

Acknowledgments: The authors appreciate the partial support of Iran Polymer and Petrochemical Institute.

Conflicts of Interest: Authors declare no conflict of interest.

\section{References}

1. Karimi, F.; Zolfigol, M.A.; Yarie, M. A novel and reusable ionically tagged nanomagnetic catalyst: Application for the preparation of 2-amino-6-(2-oxo-2H-chromen-3-yl)-4-arylnicotinonitriles via vinylogous anomeric based oxidation. Mol. Catal. 2019, 463, 20-29. [CrossRef]

2. Teimuri-Mofrad, R.; Gholamhosseini-Nazari, M.; Payami, E.; Esmati, S. Ferrocene-tagged ionic liquid stabilized on silica-coated magnetic nanoparticles: Efficient catalyst for the synthesis of 2-amino-3-cyano4H-pyran derivatives under solvent-free conditions. Appl. Organomet. Chem. 2018, 32, e3955. [CrossRef]

3. Rafiee, E.; Kahrizi, M. Mechanistic investigation of Heck reaction catalyzed by new catalytic system composed of $\mathrm{Fe}_{3} \mathrm{O}_{4} @ \mathrm{OA}-\mathrm{Pd}$ and ionic liquids as co-catalyst. J. Mol. Liq. 2016, 218, 625-631. [CrossRef]

4. Sadjadi, S.; Akbari, M.; Heravi, M.M. Palladated Nanocomposite of Halloysite-Nitrogen-Doped Porous Carbon Prepared from a Novel Cyano-/Nitrile-Free Task Specific Ionic Liquid: An Efficient Catalyst for Hydrogenation. ACS Omega 2019, 4, 19442-19451. [CrossRef] [PubMed] 
5. Öztürk, B.Ö. Ammonium tagged Hoveyda-Grubbs catalysts immobilized on magnetically separable core-shell silica supports for ring-closing metathesis reactions. Microporous Mesoporous Mater. 2018, 267, $249-256$. [CrossRef]

6. Sadjadi, S.; Heravi, M.M.; Malmir, M.; Kahangi, F.G. Ionic-liquid and cuprous sulfite containing halloysite nanoclay: An efficient catalyst for Click reaction as well as N- and O-arylations. Appl. Clay Sci. 2018, 162, 192-203. [CrossRef]

7. Sadjadi, S.; Akbari, M.; Monflier, E.; Heravi, M.M.; Leger, B. Pd nanoparticles immobilized on halloysite decorated with a cyclodextrin modified melamine-based polymer: A promising heterogeneous catalyst for hydrogenation of nitroarenes. New J. Chem. 2018, 42, 15733-15742. [CrossRef]

8. Sadjadi, S.; Koohestani, F. Functionalized chitosan polymerized with cyclodextrin decorated ionic liquid: Metal free and biocompatible catalyst for chemical transformations. Int. J. Biol. Macromol. 2020, 147, 399-407. [CrossRef]

9. Yang, Y.; Li, X.; Zhou, C.; Xiong, W.; Zeng, G.; Huang, D.; Zhang, C.; Wang, W.; Song, B.; Tang, X. Recent advances in application of graphitic carbon nitride-based catalysts for degrading organic contaminants in water through advanced oxidation processes beyond photocatalysis: A critical review. Water Res. 2020, 184, 116200. [CrossRef]

10. Sun, S.; Gou, X.; Tao, S.; Cui, J.; Li, J.; Yang, Q.; Liang, S.; Yang, Z. Mesoporous graphitic carbon nitride (gC3N4) nanosheets synthesized from carbonated beverage-reformed commercial melamine for enhanced photocatalytic hydrogen evolution. Mater. Chem. Front. 2019, 3, 597-605. [CrossRef]

11. Lau, V.W.-h.; Moudrakovski, I.; Botari, T.; Weinberger, S.; Mesch, M.B.; Duppel, V.; Senker, J.; Blum, V.; Lotsch, B.V. Rational design of carbon nitride photocatalysts by identification of cyanamide defects as catalytically relevant sites. Nat. Commun. 2016, 7, 12165. [CrossRef] [PubMed]

12. Denisov, N.; Chubenko, E.; Bondarenko, V.; Borisenko, V. Synthesis of Oxygen-Doped Graphitic Carbon Nitride from Thiourea. Tech. Phys. Lett. 2019, 45, 108-110. [CrossRef]

13. Paul, D.R.; Sharma, R.; Nehra, S.; Sharma, A. Effect of calcination temperature, $\mathrm{pH}$ and catalyst loading on photodegradation efficiency of urea derived graphitic carbon nitride towards methylene blue dye solution. RSC Adv. 2019, 9, 15381-15391. [CrossRef]

14. Reddy, K.R.; Reddy, C.V.; Nadagouda, M.N.; Shetti, N.P.; Jaesool, S.; Aminabhavi, T.M. Polymeric graphitic carbon nitride (g-C3N4)-based semiconducting nanostructured materials: Synthesis methods, properties and photocatalytic applications. J. Environ. Manag. 2019, 238, 25-40. [CrossRef] [PubMed]

15. Xu, Y.; Jiang, S.-X.; Yin, W.-J.; Sheng, W.; Wu, L.-X.; Nie, G.-Z.; Ao, Z. Adsorption behaviors of $\mathrm{HCN}_{1} \mathrm{SO}_{2}, \mathrm{H}_{2} \mathrm{~S}$ and NO molecules on graphitic carbon nitride with Mo atom decoration. Appl. Surf. Sci. 2020, 501, 144199. [CrossRef]

16. Subhan, F.; Khan, I.; Hong, J. Two-dimensional graphitic carbon nitride (g-C4N3) for superior selectivity of multiple toxic gases $\left(\mathrm{CO}, \mathrm{NO}_{2}\right.$, and $\left.\mathrm{NH}_{3}\right)$. Nanotechnology 2020, 31, 145501. [CrossRef] [PubMed]

17. Ingabire, P.B.; Pan, X.; Haragirimana, A.; Li, N.; Hu, Z.; Chen, S. Enhanced conduction capability of nanocomposite membrane of quaternized poly (arylene ether sulfone) s covalently bonded with graphitic carbon nitride nanosheets for fuel cells. React. Funct. Polym. 2019, 144, 104260. [CrossRef]

18. Dorraj, M.; Sadjadi, S.; Heravi, M.M. Pd on poly(1-vinylimidazole) decorated magnetic S-doped grafitic carbon nitride: An efficient catalyst for catalytic reduction of organic dyes. Sci. Rep. 2020, 10, 13440. [CrossRef]

19. Cha, J.S.; Park, S.H.; Jung, S.-C.; Ryu, C.; Jeon, J.-K.; Shin, M.-C.; Park, Y.-K. Production and utilization of biochar: A review. J. Ind. Eng. Chem. 2016, 40, 1-15. [CrossRef]

20. Ahmad, M.; Rajapaksha, A.U.; Lim, J.E.; Zhang, M.; Bolan, N.; Mohan, D.; Vithanage, M.; Lee, S.S.; Ok, Y.S. Biochar as a sorbent for contaminant management in soil and water: A review. Chemosphere 2014, 99, $19-33$. [CrossRef]

21. Xie, Z.-L.; Su, D.S. Ionic Liquid Based Approaches to Carbon Materials Synthesis. Eur. J. Inorg. Chem. 2015, 2015, 1137-1147. [CrossRef]

22. Konwar, L.J.; Boro, J.; Deka, D. Review on latest developments in biodiesel production using carbon-based catalysts. Renew. Sustain. Energy Rev. 2014, 29, 546-564. [CrossRef]

23. Yu, J.; Zhao, Y.; Li, Y. Utilization of corn cob biochar in a direct carbon fuel cell. J. Power Sources 2014, 270, 312-317. [CrossRef] 
24. Jiang, J.; Zhang, L.; Wang, X.; Holm, N.; Rajagopalan, K.; Chen, F.; Ma, S. Highly ordered macroporous woody biochar with ultra-high carbon content as supercapacitor electrodes. Electrochim. Acta 2013, 113, 481-489. [CrossRef]

25. Zhang, C.; Fu, Z.; Liu, Y.C.; Dai, B.; Zou, Y.; Gong, X.; Wang, Y.; Deng, X.; Wu, H.; Xu, Q.; et al. Ionic liquid-functionalized biochar sulfonic acid as a biomimetic catalyst for hydrolysis of cellulose and bamboo under microwave irradiation. Green Chem. 2012, 14, 1928-1934. [CrossRef]

26. Cai, X.; Li, J.; Liu, Y.; Yan, Z.; Tan, X.; Liu, S.; Zeng, G.; Gu, Y.; Hu, X.; Jiang, L. Titanium dioxide-coated biochar composites as adsorptive and photocatalytic degradation materials for the removal of aqueous organic pollutants. J. Chem. Technol. Biotechnol. 2018, 93, 783-791. [CrossRef]

27. Huang, X.; Liu, Y.; Liu, S.; Tan, X.; Ding, Y.; Zeng, G.; Zhou, Y.; Zhang, M.; Wang, S.; Zheng, B.; et al. Effective removal of $\mathrm{Cr}(\mathrm{VI})$ using b-cyclodextrin-chitosan modified biochars with adsorption/reduction bifuctional roles. RSC Adv. 2016, 6, 94-104. [CrossRef]

28. Liu, S.; Huang, B.; Chai, L.; Liu, Y.; Zeng, G.; Wang, X.; Zeng, W.; Shang, M.; Deng, J.; Zhou, Z. Enhancement of $\mathrm{As}(\mathrm{V})$ adsorption from aqueous solution by a magnetic chitosan/biochar composite. RSC Adv. 2017, 7, 10891-10900. [CrossRef]

29. Li, Y.; Wang, X.; Zhu, Y.; Wang, L.; Wang, Z. In situ preparation of biochar coated silica material from rice husk. Colloids Surf. A Physicochem. Eng. Asp. 2012, 395, 157-160. [CrossRef]

30. Zhang, X.; Lai, E.S.M.; Martin-Aranda, R.; Yeung, K.L. An investigation of Knoevenagel condensation reaction in microreactors using a new zeolite catalyst. Appl. Catal. A 2004, 261, 109-118. [CrossRef]

31. Tietze, L.F. Domino Reactions in Organic Synthesis. Chem. Rev. 1996, 96, 115-136. [CrossRef] [PubMed]

32. Xu, Q.; Niu, Y.; Wang, G.; Li, Y.; Zhao, Y.; Singh, V.; Niu, J.; Wang, J. Polyoxoniobates as a superior Lewis base efficiently catalyzed Knoevenagel condensation. Mol. Catal. 2018, 453, 93-99. [CrossRef]

33. Yang, Y.; Wang, D.; Jiang, P.; Gao, W.; Cong, R.; Yang, T. Structure-induced Lewis-base Ga4B2O9 and its superior performance in Knoevenagel condensation reaction. Mol. Catal. 2020, 490, 110914. [CrossRef]

34. Al-Shehri, B.M.; Shabaan, M.R.; Shkir, M.; Kaushik, A.; Hamdy, M.S. Single-step fabrication of Na-TUD-1 novel heterogeneous base nano-catalyst for Knoevenagel condensation reaction. J. Nanostrucure Chem. 2020, 1-11. [CrossRef]

35. Zhang, X.; Zhang, R.; Jin, Y.; Li, T. Two PbII-based coordination polymers based on 5-aminonicotinic acid and 5-hydroxynicotinic acid for Knoevenagel condensation reaction and luminescent sensor. J. Solid State Chem. 2019, 278, 120927. [CrossRef]

36. Burate, P.A.; Javle, B.R.; Desale, P.H.; Kinage, A.K. Amino acid amide based ionic liquid as an efficient organo-catalyst for solvent-free Knoevenagel condensation at room temperature. Catal. Lett. 2019, 149, 2368-2375. [CrossRef]

37. Sun, Z.; Yang, X.; Huang, X.; Zhang, M.; Bian, G.; Qi, Y.; Yang, X.; Zhang, W. Mesoporous polymeric catalysts with both sulfonic acid and basic amine groups for the one-pot deacetalization-Knoevenagel reaction. New J. Chem. 2019, 43, 16676-16684. [CrossRef]

38. Xu, B.; Liu, Z.; Xu, Q.; Han, X.; Ma, X.; Wang, J.; Kannan, T.; Ma, P.; Wang, J.; Niu, J. Polyoxomolybdates as efficient catalysts for Knoevenagel condensation reaction of benzaldehyde and ethyl cyanoacetate under mild condition. J. Mater. Sci. 2021, 56, 4654-4665. [CrossRef]

39. Cavallaro, G.; Milioto, S.; Parisi, F.; Lazzara, G. Halloysite Nanotubes Loaded with Calcium Hydroxide: Alkaline Fillers for the Deacidification of Waterlogged Archeological Woods. ACS Appl. Mater. Interfaces 2018, 10, 27355-27364. [CrossRef]

40. Luan, Y.; Qi, Y.; Gao, H.; Andriamitantsoa, R.S.; Zheng, N.; Wang, G. A general post-synthetic modification approach of amino-tagged metal-organic frameworks to access efficient catalysts for the Knoevenagel condensation reaction. J. Mater. Chem. A 2015, 3, 17320. [CrossRef]

41. Zaheri, H.M.; Javanshir, S.; Hemmati, B.; Dolatkhah, Z.; Fardpour, M. Magnetic core-shell Carrageenan moss $/ \mathrm{Fe}_{3} \mathrm{O}_{4}$ : A polysaccharide-based metallic nanoparticles for synthesis of pyrimidinone derivatives via Biginelli reaction. Chem. Cent. J. 2018, 12, 108. [CrossRef]

42. Kargar, S.; Elhamifar, D.; Zarnegaryan, A. Core-shell structured $\mathrm{Fe}_{3} \mathrm{O}_{4} @ \mathrm{SiO}_{2}$-supported IL/[Mo6O19]: A novel and magnetically recoverable nanocatalyst for the preparation of biologically active dihydropyrimidinones. J. Phys. Chem. Solids 2020, 146, 109601. [CrossRef]

43. Safari, J.; Zarnegar, Z. Biginelli reaction on $\mathrm{Fe}_{3} \mathrm{O}_{4}-\mathrm{MWCNT}$ nanocomposite: Excellent reactivity and facile recyclability of the catalyst combined with ultrasound irradiation. RSC Adv. 2013, 3, 17962-17967. [CrossRef] 
44. Sadjadi, S.; Koohestani, F. Bentonite with high loading of ionic liquid: A potent non-metallic catalyst for the synthesis of dihydropyrimidinones. J. Mol. Liq. 2020, 319, 114393. [CrossRef]

45. Mashhoori, M.-S.; Sandaroos, R.; Moghaddam, A.Z. Polymeric imidazolium ionic liquid-tagged manganese Schiff base complex: An efficient catalyst for the Biginelli reaction. Res. Chem. Intermed. 2020, 46, 4939-4954. [CrossRef]

46. Azizi, N.; Edrisi, M. Preparation of choline sulfate ionic liquid supported on porous graphitic carbon nitride nanosheets by simple surface modification for enhanced catalytic properties. J. Mol. Liq. 2020, 300, 112263. [CrossRef]

47. Liberto, N.A.; de Paiva Silva, S.; de Fátima, Â.; Fernandes, S.A. $\beta$-Cyclodextrin-assisted synthesis of Biginelli adducts under solvent-free conditions. Tetrahedron 2013, 69, 8245-8249. [CrossRef]

48. Kamalzare, P.; Mirza, B.; Soleimani-Amiri, S. Chitosan magnetic nanocomposite: A magnetically reusable nanocatalyst for green synthesis of Hantzsch 1, 4-dihydropyridines under solvent-free conditions. J. Nanostructure Chem. 2020, 1-15. [CrossRef]

49. Doustkhah, E.; Rostamnia, S.; Hassankhani, A. The raise of SBA-SO $3 \mathrm{H}$ catalytic activity by inducing ultrasound irradiation in the multicomponent syntheses. J. Porous Mater. 2016, 23, 549-556. [CrossRef]

50. Xin, J.; Chang, L.; Hou, Z.; Shang, D.; Liu, X.; Feng, X. An enantioselective Biginelli reaction catalyzed by a simple chiral secondary amine and achiral Brønsted acid by a dual-activation route. Chem. Eur. J. 2008, 14, 3177-3181. [CrossRef]

51. He, L.; Qin, S.; Liu, J.; Zhao, W.; Chang, T. Long-chain Brønsted acidic ionic liquids catalyzed one-pot three-component Biginelli reaction. World J. Eng. 2020, 17, 21-26. [CrossRef]

52. Suzuki, I.; Suzumura, Y.; Takeda, K. Metal triflimide as a Lewis acid catalyst for Biginelli reactions in water. Tetrahedron Lett. 2006, 47, 7861-7864. [CrossRef]

53. Kong, R.; Han, S.-B.; Wei, J.-Y.; Peng, X.-C.; Xie, Z.-B.; Gong, S.-S.; Sun, Q. Highly efficient synthesis of substituted 3, 4-Dihydropyrimidin-2-(1H)-ones (DHPMs) catalyzed by Hf(OTf)4: Mechanistic insights into reaction pathways under metal Lewis acid catalysis and solvent-free conditions. Molecules 2019, 24, 364. [CrossRef] [PubMed]

54. Ramos, L.M.; Ponce de Leon y Tobio, A.Y.; dos Santos, M.R.; de Oliveira, H.C.; Gomes, A.F.; Gozzo, F.C.; de Oliveira, A.L.; Neto, B.A. Mechanistic studies on lewis acid catalyzed biginelli reactions in ionic liquids: Evidence for the reactive intermediates and the role of the reagents. J. Org. Chem. 2012, 77, 10184-10193. [CrossRef] [PubMed]

55. Wang, Y.T.; Tang, G.M.; Wu, Y.S. A Set of phenyl sulfonate metal coordination complexes triggered Biginelli reaction for the high efficient synthesis of 3, 4-dihydropyrimidin-2 $(1 \mathrm{H})$-ones under solvent-free conditions. Appl. Organomet. Chem. 2020, 34, e5542. [CrossRef]

56. Jetti, S.R.; Upadhyaya, A.; Jain, S. 3,4-Hydropyrimidin-2-(1H) one derivatives: Solid silica-based sulfonic acid catalyzed microwave-assisted synthesis and their biological evaluation as antihypertensive and calcium channel blocking agents. Med. Chem. Res. 2014, 23, 4356-4366. [CrossRef]

57. Russowsky, D.; Canto, R.F.; Sanches, S.A.; D’Oca, M.G.; de Fátima, Â.; Pilli, R.A.; Kohn, L.K.; Antônio, M.A.; de Carvalho, J.E. Synthesis and differential antiproliferative activity of Biginelli compounds against cancer cell lines: Monastrol, oxo-monastrol and oxygenated analogues. Bioorg. Chem. 2006, 34, 173-182. [CrossRef]

58. Shumaila, A.M.; Al-Thulaia, A.A. Mini-review on the synthesis of Biginelli analogs using greener heterogeneous catalysis: Recent strategies with the support or direct catalyzing of inorganic catalysts. Synth. Commun. 2019, 49, 1613-1632. [CrossRef]

59. Sheykhan, M.; Yahyazadeh, A.; Ramezani, L. A novel cooperative Lewis acid/Brønsted base catalyst Fe3O4@ $\mathrm{SiO} 2-\mathrm{APTMS}-\mathrm{Fe}(\mathrm{OH}) 2$ : An efficient catalyst for the Biginelli reaction. Mol. Catal. 2017, 435, 166-173. [CrossRef]

60. Narayanan, D.P.; Sankaran, S.; Narayanan, B.N. Novel rice husk ash-reduced graphene oxide nanocomposite catalysts for solvent free Biginelli reaction with a statistical approach for the optimization of reaction parameters. Mater. Chem. Phys. 2019, 222, 63-74. [CrossRef]

61. Chopda, L.V.; Dave, P.N. Recent Advances in Homogeneous and Heterogeneous Catalyst in Biginelli Reaction from 2015-19: A Concise Review. ChemistrySelect 2020, 5, 5552-5572. [CrossRef]

62. Sadjadi, S.; Koohestani, F. Pd immobilized on polymeric network containing imidazolium salt, cyclodextrin and carbon nanotubes: Efficient and recyclable catalyst for the hydrogenation of nitroarenes in aqueous media. J. Mol. Liq. 2020, 301, 112414. [CrossRef]

63. Sadjadi, S. Halloysite-based hybrids/composites in catalysis. Appl. Clay Sci. 2020, 189, 105537. [CrossRef] 
64. Dehghani, S.; Sadjadi, S.; Bahri-Laleh, N.; Nekoomanesh-Haghighi, M.; Poater, A. Study of the effect of the ligand structure on the catalytic activity of Pd@ ligand decorated halloysite: Combination of experimental and computational studies. Appl. Organomet. Chem. 2019, 33, e4891. [CrossRef]

65. Sadjadi, S.; Lazzara, G.; Heravi, M.M.; Cavallaro, G. Pd supported on magnetic carbon coated halloysite as hydrogenation catalyst: Study of the contribution of carbon layer and magnetization to the catalytic activity. Appl. Clay Sci. 2019, 182, 105299. [CrossRef]

66. Sadjadi, S.; Akbari, M.; Kahangi, F.G.; Heravi, M.M. Acidic polymer containing sulfunic acid and carboxylic acid groups heterogenized with natural clay: A novel metal free and heterogeneous catalyst for acid-catalyzed reactions. Polyhedron 2020, 179, 114375. [CrossRef]

67. Yi, Q.; Qi, F.; Cheng, G.; Zhang, Y.; Xiao, B.; Hu, Z.; Liu, S.; Cai, H.; Xu, S. Thermogravimetric analysis of co-combustion of biomass and biochar. J. Therm. Anal. Calorim. 2013, 112, 1475-1479. [CrossRef]

68. Atta, A.M.; El-Mahdy, G.A.; Allohedan, H.A.; Abdullah, M.M. Synthesis and application of poly ionic liquid-based on 2-acrylamido-2-methyl propane sulfonic acid as corrosion protective film of steel. Int. J. Electrochem. Sci 2015, 10, 6106-6119.

69. Morrison, D.W.; Forbes, D.C.; Davis, J.H. Base-promoted reactions in ionic liquid solvents. The Knoevenagel and Robinson annulation reactions. Tetrahedron Lett. 2001, 42, 6053-6055. [CrossRef]

70. Javdannezhad, M.; Gorjizadeh, M.; Sayahi, M.H.; Sayyahi, S. Caffeine-loaded $\mathrm{Fe}_{3} \mathrm{O}_{4}$ nanoparticles: A new magnetically recoverable organocatalyst for Knoevenagel condensation reaction. J. Nanoanal. 2018, 5, $287-293$.

71. Das, A.; Anbu, N.; Dhakshinamoorthy, A.; Biswas, S. A highly catalytically active Hf (IV) metal-organic framework for Knoevenagel condensation. Microporous Mesoporous Mater. 2019, 284, 459-467. [CrossRef]

72. Yue, C.; Mao, A.; Wei, Y.; Lü, M. Knoevenagel condensation reaction catalyzed by task-specific ionic liquid under solvent-free conditions. Catal. Commun. 2008, 9, 1571-1574. [CrossRef]

73. Lolak, N.; Kuyuldar, E.; Burhan, H.; Goksu, H.; Akocak, S.; Sen, F. Composites of Palladium-Nickel Alloy Nanoparticles and Graphene Oxide for the Knoevenagel Condensation of Aldehydes with Malononitrile. ACS Omega 2019, 4, 6848-6853. [CrossRef] [PubMed]

74. Yao, C.; Zhou, S.; Kang, X.; Zhao, Y.; Yan, R.; Zhang, Y.; Wen, L. A Cationic Zinc-Organic Framework with Lewis Acidic and Basic Bifunctional Sites as an Efficient Solvent-Free Catalyst: $\mathrm{CO}_{2}$ Fixation and Knoevenagel Condensation Reaction. Inorg. Chem. 2018, 57, 11157-11164. [CrossRef]

75. Zhu, Z.; Fan, W.; Liu, Z.; Yu, Y.; Dong, H.; Huo, P.; Yan, Y. Fabrication of the metal-free biochar-based graphitic carbon nitride for improved 2-Mercaptobenzothiazole degradation activity. J. Photochem. Photobiol. A 2018, 358, 284-293. [CrossRef]

76. Zheng, Y.; Yang, Y.; Zhang, Y.; Zou, W.; Luo, Y.; Dong, L.; Gao, B. Facile one-step synthesis of graphitic carbon nitride-modified biochar for the removal of reactive red 120 through adsorption and photocatalytic degradation. Biochar 2019, 1, 89-96. [CrossRef]

77. Freitas, E.F.; Souza, R.Y.; Passos, S.T.; Dias, J.A.; Dias, S.C.; Neto, B.A. Tuning the Biginelli reaction mechanism by the ionic liquid effect: The combined role of supported heteropolyacid derivatives and acidic strength. RSC Adv. 2019, 9, 27125-27135. [CrossRef]

Sample Availability: Samples of the compounds are not available from the authors.

Publisher's Note: MDPI stays neutral with regard to jurisdictional claims in published maps and institutional affiliations.

(C) 2020 by the authors. Licensee MDPI, Basel, Switzerland. This article is an open access article distributed under the terms and conditions of the Creative Commons Attribution (CC BY) license (http://creativecommons.org/licenses/by/4.0/). 